\title{
Effectiveness of Farmer to Farmer Training Programme Conducted by KVKs and AEECs of Vijayapur and Bagalkot Districts of Northern Karnataka, India
}

\author{
Kavita Angadi and R.B. Belli*
}

Department of Agricultural Extension Education, College of Agriculture, Vijayapur, University of Agricultural Sciences, Dharwad-580 005, Karnataka, India

*Corresponding author

Keywords

Adoption,

Knowledge, Farmer to farmer training, Northern Karnataka

Article Info

Accepted:

10 October 2019

Available Online:

10 November 2019
A B S T R A C T

Farmer to Farmer Training Programme was started in the year of 2014-15 by Government of Karnataka and organized by ACEEs and KVKs of Vijayapur and Bagalkot districts of Northern Karnataka imparting farmer to farmer training by progressive farmers to other farmers to bring the other farmers to mainstream of agriculture. The study was conducted in Vijayapur and Bagalkot districts of Northern Karnataka during the year of 2017-19. 56.66 per cent trained farmers had medium level of knowledge followed by high $(30.00 \%)$ and low $(13.34 \%)$ and 45.00 per cent of untrained farmers had low level of knowledge followed by medium (31.66 $\%)$ and high (23.34 \%) level in Integrated Farming System. 43.34 per cent of trained farmers belonged to medium level of adoption followed by high $(31.66 \%)$ and low $(25.00 \%)$ and in case of untrained farmers 48.34 per cent of untrained farmers belonged low level of adoption followed by medium (31.66 \%) and high $(20.00 \%)$ level adoption observed in Integrated Farming System.

\section{Introduction}

Indian agriculture is very important industry therefore it acquired a strategic position in our economy. There is a huge need for revolution in Indian agriculture from persistence to modern system of scientific agriculture. Farming system of India has begun to shift from traditional to modern method of farming, primarily due to rapid development of agriculture technology. This sound transition in agricultural technology leads to knowledge gap among extension employees and farmers because of the complicated nature of different agricultural technologies. The quick transformation of industrial agriculture seeks 
of accomplishment of skills/abilities/insights on the part of farmers and extension employees for effective and efficient use.

Training plays a vital role in the development of human performance in provided circumstances. Training will provide an organized perfection in knowledge/understanding and abilities/skills which in turn helps the trainees to function various agricultural practices effectively and efficiently. Further, it is a significant method of acquiring new abilities/skills, behaviour and relevant information to prepare for or improve the effectiveness of a vocation in an enterprise. This is only possible when training is effective. The effectiveness of training course can be defined as "extent to which training helps the trainee to perform ideally in their work through the knowledge gained from either the application, skills acquired or change in attitude.

A farmer training is a comprehensive learning experience in which "learning by doing" and "seeing is believing" are among the fundamental principles of extension.

The training conditions in the mind of the farmer/respondents can efficiently generate dissonance that can hopefully lead to acceptance. Therefore, the significance of farmer training to fill the land-to-lab gap is no longer a matter of doubt. Training is an important key element in which it helps the farmers to practice various new techniques in scientific manner.

Farmer to Farmer training programme was started in the year 2014-2015 by Government of Karnataka with the aim of bringing the other farmers into mainstream of agriculture, motivating the other farmers to adoption of progressive farmers' own innovations and also technologies developed by the universities in the field of agriculture and allied field, which are adopted by progressive farmers in their own field condition.

Farmer to Farmer training is a process of providing the training by progressive/awardee farmer to other farmers, often through creation of resource called as farmer trainer.

\section{Points to be considered while selecting the farmer trainee}

While progressive/awardees farmers, are known by 'farmer-trainer' as a common term, the progressive farmers are known by some other names (e.g. community knowledge worker, farmer-promoter) may involve in different roles.

Farmer to Farmer training help in building effective, farmer centred extension system and empowering farmers as change agents for improving the livelihoods in their communities.

Extension leader/person should play key role in selecting farmer-trainers, monitoring and evaluating them. This makes the programme more accountable to community that they serve.

Farmer trainers/progressive/awardees are 'of the community'; they communicate in local language and are more sensitive to local cultures, mannerisms, farming practices and farmers' need.

Progressive/farmer-trainer should be selected on the basis of their skills and interest in sharing information about their various farming practices which can also help the other farmers to go for good farming and attain the better livelihood.

Farmer-trainer generally serves as a complement to existing extension system, rather than substitute for them. 
Training is a critical input and it assists the farmers to practice scientifically different agricultural practices. Krishi Vigyan Kendras and Agriculture Extension Education Centre conduct trainings on various elements for the transfer of technology. Similarly Farmer to Farmer training is one of them.

To bring sustainability in farm production through Integrated Farming System "Krishi Vigyan Kendra" and "Agriculture Extension Education Centre" of Vijayapur and Bagalkot, are imparting the farmer to farmer training by progressive farmer to other farmers in their jurisdictions with instructions. There were no studies in this regard the present study was designed with the objective; to know knowledge level and adoption level of trained and untrained farmers with respect to various practices of agriculture and allied field.

\section{Materials and Methods}

The study was conducted purposively in Vijayapur and Bagalkot districts of Northern Karnataka during the year 2017-19 in order to fulfil the objectives of the study. Six talukas were selected from the both the districts based on highest number of trained farmers from each taluk and from same talukas untrained farmers also selected for the study. From each selected taluk 10 trained from the list provided by AEECs and KVK of both the taluk and 10 untrained farmers were randomly selected. Sixty trained and 60 untrained farmers were selected.

Thus, a total sample of 120 farmers will be considered for the study. The ex post-facto research design was used for the study. An interview schedule was developed and used to collect the information from trained and untrained farmers. Personal interview technique was used for data collection. The data generated were analysed and presented by using mean, frequency and standard deviation.

\section{Results and Discussion}

Overall knowledge level of trained and untrained farmers with respect to Integrated Farming System

With respect to overall knowledge among the farmers from the Table 1 it was found that, most $(56.66 \%)$ of trained farmers with medium knowledge level, followed by high $(30.00 \%)$ and low (13.34 \%) knowledge level on the integrated farming system. On the other side, 45.00 per cent of untrained farmers with 'low' knowledge level, followed by medium $(31.66 \%)$ and high $(23.34 \%)$ level of knowledge on integrated farming system. The findings of the present study are in consonance with the results of Shambharkar et al., (2018), Akkammadevi Naik et al., (2018) and Jadhav (2014).

\section{Distribution of farmers based on their level of knowledge on Integrated Farming System}

Distribution of trained farmers according to the practice wise knowledge on Integrated Farming System in the Table 2 depicted that majority $(96.66 \%)$ of trained farmers with correct knowledge regarding water management practices, followed by correct knowledge on crop suitable for black soil (88.34\%), equal percentage of correct knowledge was observed in use of farm pond water and factors considered while selecting IFS in rainfed areas, measures taken to improve the soil fertility $(83.34 \%)$, components that land less farmer can also have $(81.67 \%)$, different components included under Integrated Farming System $(80.00 \%)$, practice of horticulture, commercial crops and agro forestry can lead him to get good source of income $(78.33 \%)$, mixed cropping, crop rotation, crop combination and live stock can enhance biological diversity (76.67\%), trained farmers 
had same correct knowledge about various pest management practices and soil moisture conservation practices $(75.00 \%)$, various methods followed to improve the soil physical and chemical conditions of the soil which intern helps the farmer to get increased agriculture production $(66.67 \%)$.

Further, it was noticed from the Table 2 that same per cent $(51.67 \%)$ of untrained farmers had correct knowledge regarding use of farm pond water and highest income can be obtained by including various components of IFS. Followed by 48.33 per cent of untrained had right knowledge on water management practices, 46.67 per cent of untrained farmers had right knowledge on factors considered while selecting IFS in rainfed areas and different components of Integrated Farming System, measures taken to improve the soil fertility (45.00 \%), mixed cropping, crop rotation, crop combination and live stock can enhance biological diversity and about mixed cropping, crop rotation, crop combination and live stock can enhance biological diversity (43.33\%), IFS components practiced under landless condition (38.33\%), soil moisture conservation practices $(33.34 \%)$, methods to improve the both physical and chemical conditions of the soil which in turn help the farmer to get better yield $(25.00 \%)$.

Overall adoption level of trained and untrained farmers with respect to integrated farming system

With respect to overall adoption among the farmers from the Table 3 and it depicted that, 43.34 per cent of trained had medium level of adoption, followed by high $(31.66 \%)$ and low $(25.00 \%)$ level of adoption. 48.34 per cent of untrained farmers showed low level of adoption, followed by medium (31.66 \%) and low $(20.00 \%)$ level of adoption in Integrated Farming System.

The findings of present study in line with Ashokkumar et al., (2018) and Shambharkar et al., (2018)

\section{Extent of adoption of recommended practices of integrated farming system by trained and untrained farmers}

From the Table 4 it depicted that cent per cent of trained farmers adopted the intercropping followed by practices of one or the other recommended practices like animal husbandry, mushroom production, kitchen gardening, honey bee keeping and azolla production when farmers with no cultivable land holding with them (88.33\%), adopting minimum two components of IFS (83.33\%), practice of recycling of farm waste to increase the soil fertility ( $81.67 \%)$, adopting cultural, mechanical and chemical method of pest management (75.00 \%), adopting mixed cropping, crop rotation and crop combination to enhance/maintain biological diversity (71.67 \%). Whereas equal percentage of adoption is seen in soil and moisture conservation practices and adopting ways to improve the soil physical and chemical condition. Further it was observed that nonadoption of recommended practices of IFS by trained farmers from same table depicted that majority (43.33\%) of them not adopted growing of horticulture crops to obtain higher income followed by use of farm pond water for giving protective irrigation (35.00\%), equal per cent of non-adoption seen in soil and moisture conservation practices and ways to improve the soil physical and chemical conditions (33.33\%), respectively. 
Table.1 Overall Knowledge of trained and untrained farmers with respect to Integrated Farming System

\begin{tabular}{|c|c|c|c|c|c|}
\hline $\begin{array}{l}\text { Sl. } \\
\text { No }\end{array}$ & Categories & \multicolumn{2}{|c|}{$\begin{array}{l}\text { Trained } \\
\left(n_{1}=60\right)\end{array}$} & \multicolumn{2}{|c|}{$\begin{array}{c}\text { Untrained } \\
\left(\mathbf{n}_{2}=60\right)\end{array}$} \\
\hline \multicolumn{2}{|c|}{ Integrated Farming System } & Frequency & Percentage & Frequency & Percentage \\
\hline 1. & Low (Mean- $0.425 * \mathrm{SD})$ & 8 & 13.34 & 27 & 45.00 \\
\hline 2. & Medium $($ Mean $\pm 0.425 * \mathrm{SD})$ & 34 & 56.66 & 19 & 31.66 \\
\hline \multirow[t]{3}{*}{3.} & High $($ Mean+0.425*SD) & 18 & 30.00 & 14 & 23.34 \\
\hline & Mean & \multicolumn{2}{|c|}{7.78} & \multicolumn{2}{|c|}{4.53} \\
\hline & SD & \multicolumn{2}{|c|}{1.32} & \multicolumn{2}{|c|}{2.00} \\
\hline
\end{tabular}

Table.2 Distribution of respondents based on their practice wise level of knowledge about Integrated Farming System

\begin{tabular}{|c|c|c|c|c|c|}
\hline \multirow[t]{3}{*}{$\begin{array}{l}\text { Sl. } \\
\text { No. }\end{array}$} & \multirow[t]{3}{*}{ Statements } & \multirow{2}{*}{\multicolumn{2}{|c|}{$\begin{array}{l}\text { Trained } \\
\left(n_{1}=60\right)\end{array}$}} & \multirow{2}{*}{\multicolumn{2}{|c|}{$\begin{array}{c}\text { Untrained } \\
\left(n_{2}=60\right)\end{array}$}} \\
\hline & & & & & \\
\hline & & f & $\%$ & $\mathbf{F}$ & $\%$ \\
\hline 1 & $\begin{array}{l}\text { The components included under integrated } \\
\text { farming system }\end{array}$ & 48 & 80.00 & 12 & 20.00 \\
\hline 2 & $\begin{array}{l}\text { The measures to be taken to increase the soil } \\
\text { fertility in IFS }\end{array}$ & 50 & 83.34 & 10 & 16.66 \\
\hline 3 & $\begin{array}{l}\text { The scarcity of water in dry land condition can be } \\
\text { meet by }\end{array}$ & 52 & 86.67 & 8 & 13.33 \\
\hline 4 & $\begin{array}{l}\text { The highest income can be obtained with inclusion } \\
\text { of following components of IFS }\end{array}$ & 47 & 78.33 & 13 & 21.67 \\
\hline 5 & $\begin{array}{l}\text { Components of IFS can be taken by landless } \\
\text { farmer }\end{array}$ & 49 & 81.67 & 11 & 18.33 \\
\hline 6 & $\begin{array}{l}\text { Factors considered while selecting the IFS } \\
\text { component under rain fed condition }\end{array}$ & 52 & 86.67 & 8 & 13.33 \\
\hline 7 & The crops suitable for black soil & 53 & 88.34 & 7 & 11.67 \\
\hline 8 & $\begin{array}{l}\text { The Principles under IFS which are enhancing the } \\
\text { ecological balance }\end{array}$ & 46 & 76.67 & 14 & 23.33 \\
\hline 9 & Practices done in water management & 58 & 96.66 & 2 & 03.34 \\
\hline 10 & Practice of soil moisture conservation & 45 & 75.00 & 15 & 25.00 \\
\hline 11 & $\begin{array}{l}\text { Ways to increase the Soil physical and chemical } \\
\text { condition }\end{array}$ & 40 & 66.67 & 20 & 33.33 \\
\hline 12 & $\begin{array}{l}\text { The various pest management management } \\
\text { practices followed }\end{array}$ & 45 & 75.00 & 15 & 25.00 \\
\hline
\end{tabular}


Table.3 Overall adoption level of trained and untrained farmers with respect to Integrated Farming System

\begin{tabular}{|c|c|c|c|c|c|}
\hline Sl. No & Categories & \multicolumn{2}{|c|}{$\begin{array}{l}\text { Trained } \\
\left(\mathrm{n}_{1}=60\right)\end{array}$} & \multicolumn{2}{|c|}{$\begin{array}{c}\text { Untrained } \\
\left(\mathbf{n}_{2}=60\right)\end{array}$} \\
\hline \multicolumn{2}{|c|}{ Integrated Farming System } & f & $\%$ & f & $\%$ \\
\hline 1. & Low (Mean-0.425*SD) & 15 & 25.00 & 29 & 48.34 \\
\hline 2. & Medium $($ Mean $\pm 0.425 * S D)$ & 26 & 43.34 & 19 & 31.66 \\
\hline \multirow[t]{3}{*}{3.} & High $($ Mean+0.425*SD) & 19 & 31.66 & 12 & 20.00 \\
\hline & Mean & \multicolumn{2}{|c|}{7.08} & \multicolumn{2}{|c|}{1.23} \\
\hline & SD & \multicolumn{2}{|c|}{1.40} & \multicolumn{2}{|c|}{1.45} \\
\hline
\end{tabular}

Table.4 Extent of adoption of individual practices of Integrated Farming System

\begin{tabular}{|c|c|c|c|c|c|c|c|c|c|}
\hline \multirow{3}{*}{$\begin{array}{l}\text { Sl. } \\
\text { No }\end{array}$} & \multirow{3}{*}{ Statements } & \multicolumn{4}{|c|}{ Trained $\left(n_{1}=60\right)$} & \multicolumn{4}{|c|}{ Untrained $\left(n_{2}=60\right)$} \\
\hline & & \multicolumn{2}{|r|}{$\mathbf{A}$} & \multicolumn{2}{|c|}{ NA } & \multicolumn{2}{|c|}{$\mathbf{A}$} & \multicolumn{2}{|c|}{ NA } \\
\hline & & $\mathbf{f}$ & $\%$ & $\mathbf{f}$ & $\%$ & f & $\%$ & f & $\%$ \\
\hline 1. & $\begin{array}{l}\text { Adopting minimum two } \\
\text { components of IFS }\end{array}$ & 50 & 83.33 & 10 & 16.67 & 20 & 33.33 & 40 & 66.67 \\
\hline 2. & $\begin{array}{l}\text { Adopting horticulture crops } \\
\text { to obtain highest income }\end{array}$ & 32 & 56.67 & 26 & 43.33 & 29 & 48.33 & 31 & 51.67 \\
\hline 3. & $\begin{array}{l}\text { Practicing recycling of farm } \\
\text { waste to increase soil fertility }\end{array}$ & 49 & 81.67 & 11 & 18.33 & 10 & 16.67 & 50 & 83.33 \\
\hline 4. & $\begin{array}{l}\text { Adopting Mixed cropping , } \\
\text { Crop rotation \& Crop } \\
\text { combination r } \\
\text { enhance/maintains ecological } \\
\text { diversity }\end{array}$ & 43 & 71.67 & 17 & 28.33 & 11 & 18.33 & 49 & 81.67 \\
\hline 5. & $\begin{array}{l}\text { Using farm pond water for } \\
\text { protective irrigation }\end{array}$ & 39 & 65.00 & 21 & 35.00 & 9 & 15.00 & 51 & 85.00 \\
\hline 6. & $\begin{array}{l}\text { Landless farmer can also } \\
\text { have IFS components like } \\
\text { animal husbandry, } \\
\text { mushroom production, } \\
\text { kitchen gardening, honeybee } \\
\text { keeping, dairy and azola } \\
\text { production. }\end{array}$ & 53 & 88.33 & 7 & 11.67 & 8 & 13.33 & 52 & 86.67 \\
\hline 7. & Growing of intercrops & 60 & 100.00 & 0 & 0.00 & 5 & 8.33 & 55 & 91.67 \\
\hline 8. & $\begin{array}{l}\text { Practice of soil and moisture } \\
\text { conservation activity }\end{array}$ & 40 & 66.67 & 20 & 33.33 & 7 & 11.67 & 53 & 88.33 \\
\hline 9. & $\begin{array}{l}\text { Adopting, ways to improve } \\
\text { the soil physical and } \\
\text { chemical condition }\end{array}$ & 40 & 66.67 & 20 & 33.33 & 15 & 25.00 & 45 & 75.00 \\
\hline 10. & $\begin{array}{l}\text { Adopting cultural, } \\
\text { mechanical and chemical } \\
\text { method of pest management }\end{array}$ & 45 & 75.00 & 15 & 25.00 & 40 & 66.67 & 20 & 33.33 \\
\hline
\end{tabular}


More than twenty five per cent trained farmers not adopted the mixed cropping, crop rotation and crop combination to enhance the biological diversity, cultural, mechanical and chemical method of pest control $(25.00 \%)$ and less than twenty per cent of adoption was seen various recommended practices of IFS like recycling the farm waste, adopting minimum two components of IFS and practices of one or the other recommended practices like animal husbandry, mushroom production, kitchen gardening, honey bee keeping and azolla production when farmers with no cultivable land holding with them.

From Table 4 it can be stated that majority (91.67 \%) of untrained farmers were not adopted intercropping followed by soil and moisture conservation practices $(88.33 \%)$, practices of one or the other recommended practices like animal husbandry, mushroom production, kitchen gardening, honey bee keeping and azolla production when farmers with no cultivable land holding with them (86.67 \%), using farm pond water as protective irrigation $(85.00 \%)$, recycling the farm waste $(83.33 \%)$, growing mixed crop, practice of crop rotation and growing crops in combination (81.67\%), improving the soil physical and chemical condition $(75.00 \%)$.

Further it was seen that grater (66.67\%) adoption of cultural, mechanical and chemical method of pest management followed by horticulture crops (48.33\%), adopting minimum two components of IFS (33.33\%) and only one third of untrained farmers had adoption of cultural, mechanical and chemical method of pest control.

\section{References}

Akkamahadevi Naik, M. Sreenivasulu, I. Sreenivasa Rao and Mahesh Lankati. 2018. A Study on Knowledge Level of Farmers on Organic Red Gram Cultivation Practices in Dry land Areas of Karnataka, India. Int.J.Curr.Microbiol.App.Sci. $7(03)$ : 435-440.

Shambharkar,Y, B., Sarnaik, S, D., and Khade, A, K., 2018 Knowledge and adoption behavior of bt cotton growers about integrated nutrient management practices in Yavatmal district of Vidarbha region, India. Int.J.Curr.Microbiol.App.Sci. 6:27462751.

Ashokkumar, B., Tulasiram, J., Maraddi, G, N., and Basavaraj, H., 2018 A Study on Adoption Level of Recommended Cultivation Practices of Blackgram Growers in North Eastern Karnataka, India. Int.J.Curr.Microbiol.App.Sci. 7(02): 567-574.

Jadhav, K., 2014, A comparative study of trained and untrained farmers of district agriculture training center (DATC) Vijayapur. M. Sc. (Agri.) Thesis, Univ, Agric, Sci., Dharwad (India).

\section{How to cite this article:}

Kavita Angadi and Belli, R.B. 2019. Effectiveness of Farmer to Farmer Training Programme Conducted by KVKs and AEECs of Vijayapur and Bagalkot Districts of Northern Karnataka, India. Int.J.Curr.Microbiol.App.Sci. 8(11): 1220-1226.

doi: https://doi.org/10.20546/ijcmas.2019.811.143 